\title{
REPORTS
}

\section{The Encyclopedia of Coronavirus Rumors and Fakes: A Report}

\author{
Natalie Kononenko \\ University of Alberta, Emerita \\ Waterloo, Ontario
}

Introduction

As a member of the Folklore Commission of the International Committee of Slavists, I am privileged to listen to the presentation of new research conducted in the countries of the Slavic world. On July 10, 2020, the Commission heard Nikita Petrov of the Russian Presidential Academy of National Economy and Public Administration in Moscow present the Encyclopedia of Coronavirus Rumors and Fakes. This website is run by Petrov, Aleksandra Arkhipova and their team of Dar'ia Radchenko, Anna Kirziuk, Maria Gavrilova, Irina Kozlova, Sergei Belianin and Boris Peigin. The encyclopedia can be found at the following link: https://nplus1.ru/material/2020/04/08/coronarumors.

Encyclopedia units; Unit 1: COVID lore categories

The site contains a list of types of COVID-19 folklore, or popularly generated COVID-19 stories and beliefs, identified by the Encyclopedia team. The categories isolated are:

1. Pseudo-medical advice, that is posts giving advice on preventing COVID-19 infection. The posts attribute this advice to young doctors such as Iura Klimov, presumably more believable because of their age, and to famous Israeli doctors.

2. Folk and religious cures for COVID-19 or folk and religious COVIDprevention strategies. Preventative measures include using garlic or ginger, the latter of which needs to be tied to one's foot, nailing a cross to a tree, or using olive oil to draw a cross on the inside of one's door.

3. Warnings such as notices telling people that black helicopters will be flying over the city at night to spray the area with disinfectants and that all residents should take cover and even stay away from windows to avoid harm from the disinfectant.

4. First person accounts of experiences with COVID-19 that may be real, albeit exaggerated, but which then get circulated and amplified on social media.

5. "Documents" made to look like official notices or press releases. 
6. Stories about the origin of the virus, narratives that usually suggest local government involvement or international conspiracies.

Unit 2: Examples and analysis

Scrolling down the webpage, the next section gives detailed examples and analyses of coronavirus posts collected and studied by the Encyclopedia staff. Each example is followed by the name of the Encyclopedia team member who investigated the story, gathering locations and dates of attestation, international social media parallels, and similar accounts in other media. This section of the website is essentially a series of articles, each carefully researched and documented. In addition to the reproduction of the posts that form the impetus for each story, the article offers embedded links to relevant sites.

I should note that one cannot find a collection of all of the posts of a particular type collected by the compilers of the Encyclopedia. This is not a research site where one can search through massive amounts of raw data. Rather, this is an analytical site with data that has already been processed by the staff. The examples given are the following:

Story 1: Newly introduced $5 \mathrm{G}$ network towers weaken the immune system and make people susceptible to catching the coronavirus. The discussion of this rumor includes a drawing shared online, variants of the post about the threat of $5 \mathrm{G}$, along with the places where those variants were attested. Bill Gates receives blame, just like in the West, along with entire countries, specifically the United States and China. There are accounts of supposedly real events that might have stimulated the $5 \mathrm{G}$ rumors, namely a massive bird-kill near a broadcast tower and rumors of anti-5G actions and protests in countries outside of Russia.

Story 2: Migrants spread the disease. Apparently seasonal migrant workers were left in Russia after the outbreak of the virus and were unable to return home. The Encyclopedia reproduces a web page with warnings to be wary of the migrants and their threat of bodily harm, both as desperate perpetrators of street crime and as carriers of COVID-19. The discussion notes when the rumors first appeared online. It characterizes the language used, which is surprisingly neutral and unemotional, and lists the ethnic groups most frequently identified as the types of migrants likely to pose a threat to Russians.

Story 3: Posting coronavirus jokes on social media such as WhatsApp and Instagram will be punished by a 100,000 ruble fine. Presumably "jokes" means fake news posted with the intent of being humorous. The notice was first documented in Kazakhstan in March 2020 and then spread across Russia, despite attempts by official media to declare it to be false information. The discussion states that the irrepressibility of this rumor is due to lack of trust in official bodies, combined with an expectation that any government reaction would, indeed, be excessive. The media posts apparently led to a number of pranks and, in Cheliabinsk, the pranksters did receive a fine, though not an excessive one. 
Story 4: An online warning about masks soaked in narcotics. The post relates that people are walking door-to-door, claiming that they are official representatives of the local government. They hand out masks asking the person answering the door to try the mask on for size. The treated mask causes the person who unwittingly puts it on to faint, thus allowing the imposter handing out the masks to rob the home. The text posted in Russia may be a translation of an English language warning about official-looking personnel going door-to-door in Las Vegas with a similar intent of robbing their victims. It has also appeared, often in English, in India where the rumor stated that people on the street wearing masks would offer masks similar to their own to passers-by, their intended victims. The unwitting victims faint when they put on the mask and are robbed. The shortage of protective equipment may contribute to the wide circulation of this post.

Story 5: Online warnings about thieves dressed in authentic-looking HazMat suits knocking on one's door. The people in HazMat suits arrive at an apartment saying that COVID-19 infections have been detected in the building and announcing that they must urgently decontaminate the premises. They then render the person who opens the door unconscious in a manner similar to story 4 and rob the home. Some versions of the story are made more contemporary and real by warning people to tell their children and their elderly not to answer the door. Both children and the elderly are presumed to be more gullible and, with children not in school because of the virus and with the elderly left on their own for the same reason, these groups have become especially vulnerable to thieves using threats of virus infection to deceive their victims. The team member investigating the story points out that this rumor exists in other countries, only there the people in HazMat suits talk their way into apartments in order to sell their victims fake coronavirus paraphernalia, whereas, in Russia, the intent is robbery, just as in story 4.

Story 6: A notice that elders at Mount Athos advise all Orthodox Christians to put a cross on the inside of their doors. Those who do not own a cross should draw one using olive oil. This advice is accompanied by photos of what is supposed to be Mary, Mother of God, or a cloud in her likeness, in the sky. It is she who notified the praying monks of the actions that need to be taken. There are also images showing how the cross on the door should be drawn. The pronouncement is followed by public reaction posts saying that there can be nothing wrong with drawing crosses. These posts proliferated despite clergy statements, including digital media posts, pronouncing the notices to be false. The clerics also posted information instructing people on ways to cleanse themselves of the sin of spreading false information.

The Encyclopedia staff point out that a knowledgeable person is able to detect that the posts are fake and not a pronouncement from Mount Athos because they contain stylistic problems: language patterns and terminology that would not be used by Orthodox clergy. There is also evidence of general lack of knowledge of Orthodoxy. The writer of the article of this example of COVID-19 lore draws parallels from folk responses to earlier epidemics, stating that fake ecclesiastical pronouncements are a typical reaction to situations of catastrophic illness. 
Story 7: Polina from Italy. This is a post that the afore-named Polina, a citizen of St. Petersburg, now living in Italy, shared on her Vkontakte (a Russian social media site similar to Facebook) account. She warns her fellow Russians of the dangers that are coming their way by providing a description of what she sees happening in Italy. This is presented as a first-person account - things that Polina actually witnessed - but in fact describes a general situation that the author could only have heard about, not actually seen or experienced herself. The warning became an incredibly popular post with thousands of likes and reposts. It was even picked up by Kirill, Patriarch of Moscow and all Russia, and used as a warning to the faithful. The Encyclopedia gives links to "Polina's" initial post and to the online pronouncement by Patriarch Kirill. It also gives examples of reactions that were not reposts, but confirming comments. The Encyclopedia attributes the impact and popularity of the Polina post to the fact that it is a warning of impending disaster combined with the power of the supposedly eyewitness account by a real person who was even given a last name, Golovushkina, making her all the more credible. Polina's post inspired secondary posts that confirmed the original warning by saying that the posters had friends in Italy who had described the situation there in similar terms. These secondary accounts of a disastrous situation served to strengthen the veracity of the Polina account by adding a second tier of eye-witnesses.

Story 8: A little-known Pushkin poem. A poem that seeks to console the reader by saying "this too will pass" was circulated online as a verse written by Pushkin in 1827 when he was in isolation at Boldino because of the cholera epidemic that took place during that time period. This post, too, became extremely popular with multiple likes and reposts. Unfortunately, this is not a case of Pushkin reaching out from the past to offer comfort in the present. Rather it is a contemporary creation by the Kazakh poet and blogger Urri Grim written to celebrate the Iranian/Persian holiday of Navruz, celebrated widely by Muslims in Russia and Central Asia. Apparently, a reader of Grim's posts named Seule attached the attribution to Pushkin and the year of composition and then reposted the text as a joke. She retracted her joke three minutes later but, by then, it was too late - the post had gone viral. According to the Encyclopedia, errors within Seule's attribution should have alerted readers to the fact that it was a fake, but no- the inevitable happened and the text, using the power of Pushkin's name, went viral. Who was responsible for the fake, Encyclopedia asks, and answers: everyone, but especially the readers and re-posters.

Story 9: A curfew announced in Moscow. The post in question is meant to look like an official document generated by the Ministry of Defense announcing that there will be a curfew in Moscow on 30 March 2020 between 8PM and 5AM for the purpose of a chemical treatment (presumably disinfection) of the city. The difference between this and the black helicopter story is that this post is meant to look like an official document, whereas the black helicopter warning is a personal communication from someone who, allegedly, was privy to insider information. This post was almost immediately denied by the Ministry of Defense which blamed "neighboring countries" for the false warning. The Encyclopedia staff 
argue that this is probably a hoax generated by a youngster and support their claim by citing the type of language used and the errors found in the text. The errors include formatting and content that differ from actual official notices. Finally, the Encyclopedia draws parallels to similar pronouncements during Soviet times that were circulated, not online, but on message boards.

Story 10: Vodka kills COVID-19. Almost everywhere (not only on the Internet) one can find advice stating that using vodka protects against COVID-19. The meaning of the term "using" varies and includes drinking vodka, using it as a disinfectant cleanser, and soaking masks in it so that one ends up breathing through vodka. These uses are proclaimed and supported not only by popular, but also by some government, sources including Belarusian president Lukashenka. Advice that urges the populace to use vodka can be serious and it can be humorous. In the latter case, it serves to trivialize the threat of the pandemic. As the Encyclopedia explains, Russians and Belarusians have long accepted vodka as a cure-all but, in the West, this is a new idea. In one series of posts, Western recommendations to resort to vodka are attributed to St. Luke's hospital in Kansas City. In Japan, the use of vodka was advocated by a journalist who proposed it as an effective alternative in the absence of hand sanitizer. Drinking vodka as a prophylactic led to tragic consequences in Iran where alcoholic beverages are banned, and people turned to bootlegged spirits, apparently methanol, and died. In Russia, attempts to discourage the use of vodka fell on deaf ears and the Encyclopedia explains this by the fact that, in problematic situations, people often turn to commonly available substances such as garlic, ginger and, of course, vodka. Vodka also has a pronounced flavor and is psychoactive, reminding people of medicine. The last argument in support of the use of vodka is that it is perceived as native, a truly Russian substance, and thus effective against illnesses that come from a foreign source.

Story 11: Water of life/water of death. In February 2020, rumors started in Tomsk, Novosibirsk, and Kemerovo that local authorities were adding disinfectant to the drinking water, making it unsafe to drink. These rumors were believed because certain infections, such as cholera and bubonic plague, can, indeed, be water-borne. The other basis for their believability is that cities have, in the past, added disinfectant to drinking water when there were threats of hepatitis A and other infections. Of course, when actual massive treatment of drinking water occurs, the public is officially notified; there is no need for rumors. Rumors about water made dangerous with disinfectant seem to have originated in Hong Kong. A drinking water rumor in France held that the municipal water supply carried the coronavirus itself. In China, there was a post that authorities were adding chlorine in maximum concentration to the drinking water, making it unsafe to drink. Chinese rumors, the Encyclopedia proposes, spread to Russia and then to Europe. There were even comic versions of the rumors, namely notices that the city had added alcohol to the drinking water. These were meant to discredit the original warnings.

Story 12: An open letter from Russian doctors. An open letter, claiming to be from the Association of Russian Physicians to President Putin, the Government 
of Russia, and various other officials circulated online. It contains a series of warnings, essentially stating that the coronavirus epidemic is non-existent and that it is a hoax meant to facilitate control of the population. Other points in the open letter state that making people deathly afraid makes them easily manageable, that coronavirus threats are an international conspiracy aimed at creating an electronic concentration camp, that coronavirus is a plot by the world's ultra-rich, that the quarantine is a pretext for introducing a $5 \mathrm{G}$ network, and that threats of the virus are a way to microchip the population. The discussion provided by the Encyclopedia staff points out that the above-named association of physicians does not exist and is the fictive creation of the Russian Rebirth Party. The "open letter" was made believable by its references to experts and its publication on parents' and workers' chat groups. The text first appeared on April 1 and many of its recipients took it as an April Fool's joke, but its widespread republication, its official appearance, and its endorsement by individuals personally known to recipients added to its credibility. The Encyclopedia lists various internal errors and contradictions which show that the "open letter" is a fake. Nonetheless, people, not just in Russia, but in the United States and elsewhere, are willing to believe that there are government conspiracies aimed at controlling the population and the Encyclopedia lists past instances when such conspiracy rumors circulated.

\section{Unit 3: Requests to readers for new information}

The list of stories is followed by a request to the readership of the site to share their own experiences with coronavirus rumors and fakes. Those submitting are asked to fill out a set of forms that ask for the rumor, its source, and the geographical location of the person supplying the information; the person's age and gender are also requested. The forms further ask for the platform on which the rumor or fake was first encountered. The respondent is then asked to evaluate the credibility of the post and is prompted to reproduce the post (screen capture), if possible. At the end, the respondent has an opportunity to provide an email address, should s/he wish to communicate further with the Encyclopedia staff.

\section{Attribution}

At the bottom of the page there is a signature stating that the Encyclopedia is the work of the Laboratory for Theoretical Folkloristics at the School of Humanistic Studies of the Russian Presidential Academy of National Economy and Public Administration. The Laboratory's members and their guest contributors are again listed. The preparers of the Coronavirus Encyclopedia, and the members of the Laboratory of Theoretical Folkloristics as a whole, have a general interest in folklore. One of their posts is the discussion of a legend that recounts how a young woman committed a sacrilegious act by dancing with the icon of St. Nicholas and was punished for her transgressions. The event took place during the Soviet era in Kuibyshev and the post features an account of the legend, photos of icons depicting the event, narratives of related miracles, and a discussion 
of folkloric parallels. In short, the members of the Laboratory of Theoretical Folkloristics are producing a treasure trove of carefully processed Russian folk belief and narrative.

The Laboratory for Theoretical Folklore Studies

While the future of the Coronavirus Rumors and Fakes project is not apparent from the website given above, communication with the staff at the Laboratory for Theoretical Folklore Studies informed this author and the Folklorica staff that further work, based on more recent materials, is planned. They referred us to the following English-language site: https://www.monitoringjournal.ru/index.php/monitoring/article/view/1778? fbcli d=IwAR0CeHHidPlwKTOFKkILp1H4FG7fbWy7rKMV RHJJQZUoPX0SceN Bxu0ooE. It provides information about the Monitoring of Public Opinion: $\overline{\text { Economic }}$ and Social Changes Journal. They also recommended the main site of the Laboratory of Theoretical Folkloristics (http://shagi.ranepa.ru/lab/folc). Here users can find a list of the Laboratory's projects, publications, and researchers.

The members of the Laboratory of Theoretical Folkloristics were kind enough to also provide us with a description of their research interests and their approach to their work. Their team emphasizes fieldwork and making every effort to capture and study the expressions and the practices of communities as produced by the people themselves. Their regional focus is Russia and Eurasia. They seek to uncover those cultural texts that a society creates about itself, hoping to help educate a citizenry free of ideological manipulation. The Laboratory is currently working on three projects.

The first is run by Sergei Nekliudov and deals with semiotic ideology and the logic of meaning creation in folklore texts. Drawing on the concept of linguistic ideology, this project seeks to understand the emic process of symbol creation and decoding, emphasizing the functionally semantic level of the study of tradition. Comparing emic and etic views allows researchers to see the normative hermeneutics of a culture. Looking at a culture as an assemblage of semiotic ideology helps access the depth and complexity of culture as a living process.

The second project, run by Nikita Petrov, deals with twentieth- and twentyfirst-century folklore and post-folklore in urban environments and emphasizes narrative and behavioral strategies. It looks at the growth of new media, its bearing on the transmission of texts, and the impact of those texts on the landscape of the city. The main goal of the project is to study the cultural mechanisms at the basis of the transmission of city lore and the reasons why people react to events in a particular and communal way.

The third project is also run by Petrov and looks at the contemporary city and its cultural texts and street practices. It examines city texts and practices (from meetings to rituals in public places) looking for development and change. The goal is to find expressions of vernacular culture and to understand their mass appeal. 
The Russian Presidential Academy of National Economy and Public Administration website

The Encyclopedia of Coronavirus Rumors and Fakes is one unit of the Russian Presidential Academy of National Economy and Public Administration website. The site also contains units on physics, astronomy, biology, and robots and drones. It has a sub-unit with current coronavirus information, including very recent material such as information on the Pfizer, AstraZeneca, and other vaccines. The current coronavirus facts page has sub-headings with information on the long-term effects of COVID-19 in those who have recovered from the disease, information on what characterizes a super-spreader event, a discussion of the relationship between blood type and susceptibility, descriptions of differences between Russian vaccines and those produced elsewhere, and other current information.

In sum, the efforts of the Russian Presidential Academy of National Economy and Public Administration are impressive, and the Laboratory of Theoretical Folkloristics is doing cutting edge research. Their Encyclopedia of Coronavirus Rumors and Fakes deserves attention and emulation. 